\title{
Plasmid Mediated Quinolones Resistance ESBL-Enterobactériaceae in Moroccan
}

\author{
EL Malki Fatima1, EL Bouraissi Meriem² and Barrijal Said²*
}

${ }^{1}$ Institut Pasteur du Maroc of Tangier, Morocco

${ }^{2}$ Faculty of Sciences and Techniques, Tangier, Morocco

\begin{abstract}
Multidrug Resistance (MDR) in Enterobacteriaceae including resistance to quinolones is rising worldwide. This study was conducted to assess the resistance level to antibiotics and to detect plasmid genes mediated quinolones resistance in Extended-Spectrum $\beta$-lactamase (ESBL)-producing Enterobacteriaceae collected from regional hospitals of Fes-Meknes in central Morocco. ESBL phenotype was determined according to the combination disc method recommended by the Clinical and Laboratory Standards Institute (CLSI) using double disc synergy test (DDST). The antimicrobial susceptibility patterns of isolates showed high resistance rate to most antibiotics except imipenem which showed $100 \%$ of susceptibility.

A sub-site of 27 isolates was screened for qnr genes by multiplex PCR. qnrB gene was detected in 8 ESBL isolates $(2 \mathrm{E}$. coli, $4 \mathrm{~K}$. pneumoniae, $01 \mathrm{E}$. aerogenes and $01 \mathrm{C}$. freundii) while no qnrA neither qnrS could be detected. aac(60)-lb-cr gene was detected in 15 strains, 13 of them were ESBL.

Our results are in agreement with the general rule that imipenem stays the drug of choice for the treatment of infections caused by ESBL producers. Moreover, the presence of qnr determinants is closely related to ESBL phenotype while aac(60)-Ib-cr gene could be detected in isolates with or without ESBL phenotype.
\end{abstract}

Keywords: Enterobacteriaceae; ESBL; Qquinolone; Plasmid genes

\section{Introduction}

Enterobacteriaceae represent the major class of Gram Negative Bacteria (GNB) responsible for the majority of infectious diseases. They acquired mechanisms of resistance to various families of antibiotics [1].

Although quinolone resistance in Enterobacteriaceae results mostly from chromosomal mutations, it may also be mediated by plasmidencoded Qnr genes [2]. Qnr proteins have been identified worldwide with a frequent association with clavulanate inhibited expandedspectrum $\beta$-lactamases and plasmid-mediated cephalosporinases. Qnr proteins protect DNA from the inhibitory activity of quinolones such as nalidixic acid.

The first transferable plasmid-encoded quinolone resistance gene ( $q n r A, q n r B$ and $q n r S)$ was isolated from a clinical isolate of ciprofloxacin- resistant Klebsiella pneumonia in 1998 [3].

The isolated $q n r A, q n r B$ and $q n r S$ gene products protect DNA gyrase from inhibition by ciprofloxacin [4].

QnrB determinants are associated with the ESBL SHV-12 inch several isolates which may explain in part the frequent association between fluoroquinolone and expanded-spectrum cephalosporin resistance in Enterobacteriaceae [4,5].

Two other plasmid-mediated quinolone resistance mechanisms have been described. The aac (60)-Ib-cr determinant, a variant of aminoglycoside acetyltransferase capable of modifying ciprofloxacin and reducing its activity, is widely prevalent and seems to be associated to $q n r$ genes [6-9].

The other is the quinolone efflux pump gene, qepA, and is mediated by a probable transposable element flanked by two copies of IS26 $[10,11]$.

The emergence of plasmid-mediated quinolone resistance determinants in Enterobacteriaceae may compromise further the efficacy of quinolones that are, together with $\beta$-lactams and aminosides, the most commonly prescribed antibiotics for treating human infections.

The aim of this study is to evaluate the efficiency of divers antibiotic classes in multidrug resistance and also to assess an eventual correlation between the presence of $q n r$ and $a a c(60)-I b-c r$ genes and the ESBLproduction from Enterobacteriaceae in Morocco.

\section{Material and Methods}

\section{Bacterial isolates}

We examined 148 Entrerobacteriaceae (E. coli $=96$; Klebseilla spp. $=40$; others $=12$ ) collected from hospital bacteriological laboratories in Fes-Maknes region during 2010 (from 1th July to $30^{\text {th }}$ September). They were isolated from urinary samples $(\mathrm{n}=97)$, surgical wound sepsis $(n=24)$, blood cultures $(n=15)$, genital tract infections $(n=05)$, catheter (04), endotracheal tube-associated pneumonias $(n=03)$.

Identification of species was carried out by API 20E (Bio-Mérieux SA, France).

\section{ESBL detection methods}

ESBL screening and confirmation were performed according to the

*Corresponding author: Barrijal Said, Faculty of Sciences and Techniques, Tangier, Morocco, E-mail: barrijal@yahoo.fr

Received March 16, 2012; Accepted May 25, 2012; Published April 27, 2012

Citation: Malki Fatima EL, Bouraissi Meriem EL, Said B (2012) Plasmid Mediated Quinolones Resistance ESBL-Enterobactériaceae in Moroccan. Pharmaceut Anal Acta S15. doi:10.4172/2153-2435.S15-006

Copyright: (c) 2012 Malki Fatima EL, et al. This is an open-access article distributed under the terms of the Creative Commons Attribution License, which permits unrestricted use, distribution, and reproduction in any medium, provided the original author and source are credited. 
Clinical and Laboratory Standards Institute (CLSI, 2008) [12] criteria. All isolates were tested by double disc synergy test (DDST) described by Jarlier [13].

ESBL producer was detected by using a disc containing ceftazidime (CAZ, $30 \mu \mathrm{g}$ ) or cefotaxime (CTX, $30 \mu \mathrm{g})$ in combination with and without clavulanic acid (CLA, $10 \mu \mathrm{g})$. The presence of an ESBL was determined by a $05 \mathrm{~mm}$ increase in zone diameters for CAZ/CLA and CTX/CLA compared with those for CAZ and CTX, respectively (Figure 1).

\section{Antibiotic susceptibility}

Susceptibility and synergy-testing for ESBLs were simultaneously performed on Mueller- Hinton agar. The following antibiotic disks (Bio- Rad) were tested: amoxicillin (AMX), amoxicillin-clavulanic acid (AMC), cefalotin (CF), cefotaxime (CTX), ceftazidin (CAZ), cefuroxime (CRO), imipenem (IPM), Tobramycin (TB), ofloxacin (OFX), ciprofloxacin (CIP), norfloxacin (NOR), corticomoxasol (SXT), colistin (CL).

The reference strains were E. coli ATCC 25922 and K. pneumoniae ATCC 700603.

\section{PCR Amplification and Molecular Detection of $q n r$ and $\operatorname{aac}(60)-I b$-cr genes}

A subset of 27 non-duplicates isolates (16 E. coli, 09 Kleb. spp, 01 E. aerogenes and $01 \mathrm{C}$. freundii) was subjected to molecular analysis. The characteristics of those isolates are listed in Table 2.

DNA preparation was performed by a boiling technique including a heating step at $100 \mathrm{C}$ of a single colony in a total volume of $100 \mu \mathrm{L}$ of distilled water followed by centrifugation of the cell suspension.

A multiplex PCR was used to detect simultaneously $q n r A, q n r B$ and qnrS genes [14,15].

The amplified DNA products were examined as described
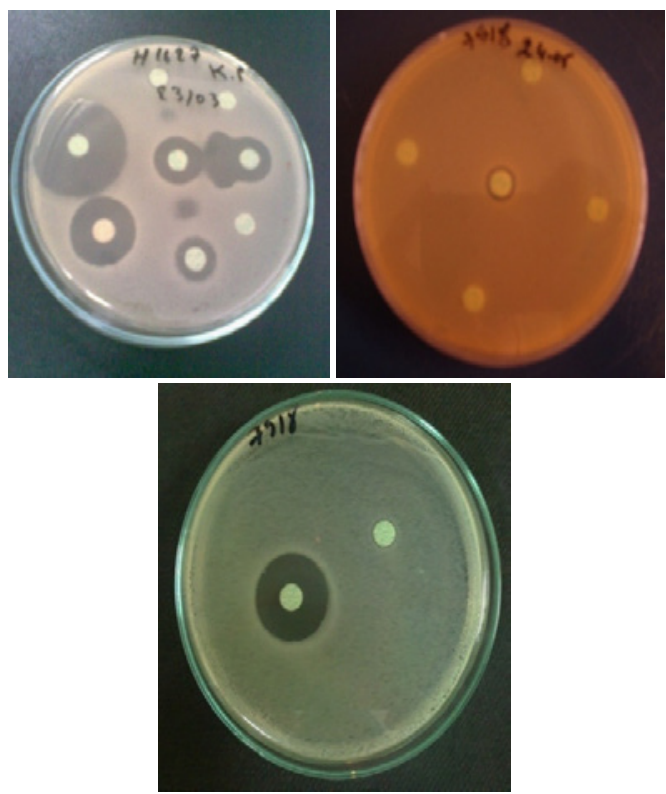

Figure 1: Appearance of ESBL-producing isolates. (a): Klebsiella pneumonia with clear zone synergy between amoxicillin. previously; the expected sizes for $q n r A, q n r B$ and $q n r S$ were 580, 264 and 428 bp respectively.

A pair of degenerated primers was specifically choused to amplify variants of $q \eta r B$ and another pair of primers was used to detect the $a a c(60)-I b-c r$ in selected stains. The expected size was 473 bp (result none shown).

DNA amplification was carried out by using $2 \mu \mathrm{l}$ of the extract in $500 \mathrm{mM}, 2 \mathrm{mM} \mathrm{KCl}, 10 \mathrm{mM}$ Tris $\mathrm{HCl}, 1.5 \mathrm{mM} \mathrm{MgCl}$, containing 500 $\mu \mathrm{M}$ of each dNTP, $0.2 \mu \mathrm{M}$ of each primer, $0.5 \mathrm{U}$ of Taq DNA polymerase (Roche Diagnostics, France) in a final volume of $25 \mu$ l.

PCR products were analyzed by electrophoresis in $1.2 \%$ agarose gel in TBE buffer staining with ethidium bromide and visualized with UV light.

\section{Result and Discussion}

\section{Phenotypic detection and antimicrobial susceptibility patterns}

The antimicrobial susceptibility patterns of isolates were examined. Enterobacteriaceae showed high resistance rate to $\beta$-lactam in general with values surrounding $80 \%$ for amoxicillin, $60 \%$ for clavulanic acid, $40 \%$ for cephalosporin of first generation (C1G) and 30\% for cephalosporin of third generation (C3G). $56 \%$ of isolates were resistant to sulfamethoxazole/ trimethoprim (SXT). Resistance to fluoroquinolones showed a rate of about $40 \%$, whereas for the tested aminoglycosides (tobramycin) is only $14 \%$. Colistin stills an efficient antibiotic against Enterobactériaceae with $96 \%$ of susceptibility while all examined isolates were susceptible to imipenem (Table 1).

The high ratio of co-resistance to quinolone, trimethoprim/ sulfamethoxazole and aminoglycosides among ESBL producers collected from this region has greatly limited the therapeutic role of those classes of antibiotics. However, our results are in agreement with the general rule that imipenem stays the drug of choice for the treatment of infections caused by ESBL producers.

Clavulanic acid and 3 surrounding cephalosporins CAZ, CTX and ATM;

ESBL-producer E.coli detected by DDST using CTX in combination without (b1) and with (b2) CLA showing increased zone inhibition diameter for CTX/CLA.

ESBL test revealed that 13 of 27 isolates were ESBL- producers (5 E. coli, $6 \mathrm{~K}$ pneumonia, $1 \mathrm{~K}$. oxytoka and 1 E. aerogenes). 11 isolates presented resistance simultaneously to $\beta$-lactam, quinolones and aminosides (Table 2). This may be explaining by the association of antibiotic resistance genes between fluoroquinolone and expandedspectrum cephalosporin in Enterobacteriaceae.

\section{Prevalence of $q n r$ and $a a c(60)-I b-c r$ genes}

Screening of $q n r$ genes resulted in 8 positives cases all of them carried qnrB-like gene with the expected size (2 E. coli, 4 K. pneumoniae, 01 E. aerogenes and 01 C. freundii), while no qnrA neither qnrS could be detected (result non shown. The rate of $q n r$ carriage among $K$. pneumonia was higher than in E. coli. To date, qnr genes have been widely detected worldwide.

The 27 analyzed isolates showed the presence of $a a c(60)-I b-c r$ 
Citation: Malki Fatima EL, Bouraissi Meriem EL, Said B (2012) Plasmid Mediated Quinolones Resistance ESBL-Enterobactériaceae in Moroccan. Pharmaceut Anal Acta S15. doi:10.4172/2153-2435.S15-006

Page 3 of 4

\begin{tabular}{|c|c|c|c|c|}
\hline Antibiotic & $\begin{array}{c}\text { E.coli } \\
\mathrm{n}=96(\%)\end{array}$ & $\begin{array}{c}\text { Klebseilla spp } \\
\mathrm{n}=40(\%)\end{array}$ & $\begin{array}{c}\text { Other } \\
\mathrm{n}=12(\%)\end{array}$ & $\begin{array}{c}\text { Total } \\
\mathrm{N}=148(\%)\end{array}$ \\
\hline AMX & $67(69,79)$ & $40(100)$ & $10(83,33)$ & $117(79,05)$ \\
\hline AMC & $51(53,12)$ & $30(75)$ & $10(83,33)$ & $91(61,48)$ \\
\hline CF & $30(31,25)$ & $22(55)$ & $8(66,66)$ & $60(40)$ \\
\hline CTX & $24(25)$ & $17(42,5)$ & $5(41,66)$ & $46(31,08)$ \\
\hline CAZ & $24(25)$ & $18(45)$ & $5(41,66)$ & $47(31,75)$ \\
\hline CRO & $24(25)$ & $18(45)$ & $5(41,66)$ & $47(31,75)$ \\
\hline IPM & 0 & 0 & 0 & 0 \\
\hline TM & $17(17,7)$ & $4(10)$ & 0 & $21(14,18)$ \\
\hline OFX & $40(41,66)$ & $17(42,5)$ & $5(41,66)$ & $62(41,89)$ \\
\hline CIP & $40(41,66)$ & $17(42,5)$ & $5(41,66)$ & $62(41,89)$ \\
\hline NOR & $40(41,66)$ & $15(37,5)$ & $5(41,66)$ & $60(40)$ \\
\hline SXT & $55(57,29)$ & $24(60)$ & $4(33,33)$ & $83(56,08)$ \\
\hline $\mathrm{CL}$ & $4(4,16)$ & 0 & $2(16,66)$ & $6(4,04)$ \\
\hline
\end{tabular}

Table 1: Antibiotic resistance profile of the bacterial isolates.

\begin{tabular}{|c|c|c|c|c|c|}
\hline Isolate & Species & BLSE : 13 & qnr: 8 & Aac: 15 & Resistance profile \\
\hline E1 & E.C & - & - & - & AMX, AMC, CF,CTX, CRO, CAZ, OFX,CIP,NOR, NET, SXT] \\
\hline E2 & E.C & + & - & + & AMX,AMC,CF,CTX,CRO,CAZ,OFX,CIP,NOR,TM,NET,SXT]NA=I \\
\hline E3 & E.C & + & - & + & AMX,AMC,CF,CRO,CAZ,CTX,OFX,CIP,NOR,NA,NET,AK,SXT \\
\hline E4 & E. aero & + & + & + & [AMX,AMC,CF, CRO,CAZ,CTX, OFX,CIP,NOR,NET,SXT,CL]I=NA \\
\hline E5 & E.C & + & + & + & AMX, AMC,CF, CTX ,CRO,CAZ,OFX, CIP, NOR,SXT,NET,CL \\
\hline E6 & K.P & + & + & + & AMC, AMX, CF, CTX, CRO, CAZ, CIP,NOR, OFX, NET, SXT \\
\hline E7 & K.P & + & + & + & AMX, AMC, CF, CTX, CRO, CAZ, CIP, OFX, NOR,NET, SXT \\
\hline E8 & K.P & + & - & + & AMX, AMC ,CF, CRO, CTX, CIP, OFX,NOR, NET,TOB, SXT \\
\hline E9 & E.C & + & - & + & AMX, AMC, CF, CTX, CRO, CAZ, CIP, NOR, OFX, NET, TOB, SXT \\
\hline E10 & E.C & - & - & - & AMX,AMC, CF, CAZ, NOR, OFX, CIP, \\
\hline E11 & K.P & + & + & + & AMX,AMC,CF,CTX,CAZ,CRO,CIP,OFX,NOR,TOB,NET,SXT] NA=I \\
\hline E12 & K.P & + & + & + & AMX, AMC,CF, CTX, CRO, CAZ, CIP,OFX, NOR, TOB,NET, SXT \\
\hline E13 & K.O & + & - & + & AMX, AMC, CF, CTX, CRO, CAZ, CIP/ NOR/ OFX, NET, TOB, SXT \\
\hline E14 & E.C & - & - & - & AMX, AMC, CIP,NOR, OFX, SXT \\
\hline E15 & E.C & - & - & - & AMX, AMC, CIP, OFX NOR, SXT, \\
\hline E16 & CITRO & - & + & - & AMX, AMC, CIP, NA, SXT \\
\hline E17 & K.O & - & - & - & AMX, AMC, CF, CRO, CAZ, TOB, SXT \\
\hline E18 & E.C & - & - & - & AMX,AMC ,NOR,OFX,CIP,,SXT, CL \\
\hline E19 & E.C & - & - & + & AMX, AMC, CIP,OFX, NOR, SXT \\
\hline E20 & E.C & - & - & - & AMX, AMC, CIP, OFX \\
\hline E21 & K.O & - & - & 一 & AMX, OFX, CIP, NOR, NET, SXT \\
\hline E22 & K.P & + & - & + & AMX, AMC, CF, CTX, CRO, CAZ, TOB \\
\hline E23 & E.C & - & - & + & AMX, AMC,CF,NA,NOR,OFX,CIP, SXT \\
\hline E24 & E.C & - & - & - & AMX, AMC, CF, CIP, OFX,NOR TOB, SXT \\
\hline E25 & E.C & - & - & - & AMX, CIP,NOR, OFX, SXT \\
\hline E26 & E.C & - & - & - & AMX, CF, CTX, CRO, CAZ, SXT \\
\hline E27 & E.C & + & + & + & AMX,AMC,CF,CRO,CAZ, CTX, NOR, OFX,CIP, NET, TOB, SXT, CL \\
\hline E28 & E.C & - & - & - & TEMOIN SENSIBLE \\
\hline
\end{tabular}

variant gene with the expected size in 15 strains (result non shown), 13 of them were ESBL. All $q n r$ strains showed ESBL phenotype and possessed aac (60)-Ib-cr determinant except a C. freundii which carried only $Q n r B$ gene and showed relatively a lower resistance profile (Table 2). The rate of $a a c$ (60)-Ib-cr carriage was comparable between E. coli and klebseilla.

Plasmid-mediated genes, such as $q n r$ and $a a c(60)-I b-c r$, may facilitate spread and increase the prevalence of quinolone-resistant strains.

The aac (60)-Ib-cr gene was detected in non-ESBL-producing $E$. coli isolates which were $\mathrm{C} 3 \mathrm{G}$ and aminoglycosides susceptible.

\section{Conclusion}

Total results obtained for this work is summarized in Table 2 with phenotypic and genotypic patterns. Further study is required to precise $a a c$ (60)-Ib-cr functions and relationship with divers' classes of antibiotics resistance. Furthermore, plasmid's carriage of these genes ( $q n r$ and $a a c(60)-I b-c r$ ) is assessed by conjugation test while the identification of divers variants is running by sequencing.

\section{References}

1. Paterson DL, Bonomo RA (2005) Extended-spectrum beta-lactamases: a clinical update. Clin Microbiol Rev 18: 657-686.

2. Poirel L, Pitout JD, Calvo L, Rodriguez-Martinez JM, Church D, et al. (2006) In 
Citation: Malki Fatima EL, Bouraissi Meriem EL, Said B (2012) Plasmid Mediated Quinolones Resistance ESBL-Enterobactériaceae in Moroccan Pharmaceut Anal Acta S15. doi:10.4172/2153-2435.S15-006

vivo selection of fluoroquinolone-resistant Escherichia coli isolates expressing plasmid-mediated quinolone resistance and expanded-spectrum betalactamase. Antimicrob Agents Chemother 50: 1525-1527.

3. Martinez-Martinez L, Pascual A, Jacoby GA (1998) Quinolone resistance from a transferable plasmid. Lancet 351: 797-799.

4. Wu JJ, Ko WC, Tsai SH, Yan JJ (2007) Prevalence of plasmid-mediated quinolone resistance determinants, QnrA, QnrB, and QnrS, among clinical isolates of Enterobacter cloacae in a Taiwanese hospital. Antimicrob Agents Chemother 51: 1223-1227.

5. Jiang Y, Zhou Z, Qian Y, Wei Z, Yu Y, et al. (2008) Plasmid-mediated quinolone resistance determinants qnr and aac(60)-lb-cr in extended-spectrum betalactamase-producing Escherichia coli and Klebsiella pneumoniae in China. $J$ Antimicrob Chemother 61: 1003-1006.

6. Robicsek A, Strahilevitz J, Jacoby GA, Macielag M, Abbanat D, et al (2006) Fluoroquinolone-modifying enzyme: a new adaptation of a common aminoglycoside acetyltransferase. Nat Med 12: 83-88.

7. Wang M, Tran JH, Jacoby GA, Zhang Y, Wang F, et al. (2003) Plasmidmediated quinolone resistance in clinical isolates of Escherichia coli from Shanghai, China. Antimicrob Agents Chemother 47: 2242-2248.

8. Karisik E, Ellington MJ, Pike R (2006) Wide occurrence of the fluoroquinolonemodifying acetyltransferase gene aac(60)-lb-cr in CTX-M-positive Escherichia coli from the United Kingdom. 46th Inter science Conference on Antimicrobial Agents and Chemotherapy, San Francisco, CA, USA.
9. Pitout JD, Wei Y, Church DL, Gregson DB (2008) Surveillance for plasmidmediated quinolone resistance determinants in Enterobacteriaceae within the Calgary Health Region, Canada: the emergence of aac(60)-lb-cr. J Antimicrob Chemother 61: 999-1002.

10. Yamane K, Wachino J, Suzuki S, Kimura K, Shibata N, et al. (2007) New plasmid-mediated fluoroquinolone efflux pump, QepA, found in an Escherichia coli clinical isolate. Antimicrob Agents Chemother 51: 3354-3360.

11. Cattoir V, Poirel L, Nordmann P (2008) Plasmid-Mediated Quinolone Resistance Pump QepA2 in an Escherichia coli Isolate from France. Antimicrob Agents and Chemother 52: 3801-3804.

12. wilker MA (2008) Performance Standards for Antimicrobial Susceptibility Testing; 18th Informational Supplement. 18edt, Clinical and Laboratory Standards Institute, Wayne, PA

13. Jarlier V, Nicolas MH, Fournier G, Philippon A (1988) Extended-spectrum b-lactamases conferring transferrable resistance to newer blactam agents in Enterobacteriaceae: hospital prevalence and susceptibility patterns. Rev Infect Dis 10: 867-878

14. Cattoir V, Poirel L, Rotimi V, Soussy CJ, Nordmann P (2007) Multiplex PCR for detection of plasmid-mediated quinolone resistance qnr genes in ESBLproducing enterobacterial isolates. J Antimicrob Chemother 60: 394-397.

15. Nordmann P, and Poirel L (2005) Emergence of plasmid-mediated resistance to quinolones in Enterobacteriaceae. J Antimicrob Chemother 56: 463-469. 